\title{
NOTAS \\ LECTURA (SINTÁCTICA) DEL PRIMER SONETO DE GARCILASO
}

Decir algo sobre esta composición hasta parece temerario. Quizá el único comentarista sensato fue Francisco Sánchez, quien le dedicó, sin pensar en variantes ni en la legitimidad de su versión, no más de cuatro líneas (trivialidades, opina Glacer) sobre un texto de Plutarco que, en su opinión, alude al tema del soneto. Herrera consiente más a su posible lector; trae antecedentes (el soneto 30 de Petrarca), muestra consecuencias literarias, la imitación de Mal Lara ("Volviendo por las horas que he perdido") y destaca el ejercicio original que le corresponde por su "modo de anotar", pero sin insistir demasiado en lo obvio, "porque se seguiría de ello fastidio y crecer estas ilustraciones en más que la justa grandeza, y vendría a hacer con esto ejercicio de gramático"1, ejercicio que es tema de estas páginas.

Aunque la tradición, el criterio o el gusto general declaren que ésta es una composición de amor² (aún hoy, a la menor provocación en contrario, los interlocutores salen en defensa del asunto), nada asegura que estos versos tan escuetos no describan un estado de ánimo ajeno al amor e incluso no sean simplemente, o en especial, un ejercicio poético económico y de buena factura a pesar de que sea "primerizo", detalle que la crítica nunca pasa por alto.

La metáfora que domina, que hace, el primer cuarteto ${ }^{3}$ es lugar común en la lírica de esa y otras épocas, y por esa materia, tan aso-

${ }^{1}$ Cito por la segunda edición de Gallego Morel, Madrid, Gredos, 1972, p. 317.

${ }^{2}$ Forzado incluso en otra versión que, con el pretexto de la hipometría del verso diez, añade el pronombre para componerlo: "si ella quisiere..." En su comentario al primer verso, dice HERRERA que "Cuando es prefación de toda la obra y de sus amores y proposición con la contemplación y vista de presente y pasado" (ed. cit., p. 315).

3 "Metáfora del camino peligroso" dice Elias RIVERs en su introducción al soneto I (Castalia, 1974, p. 65); la encuentra además en el son. VI ("por ásperos caminos he venido"), XXXVIII ("que viéndome do estoy y en lo que andado"), en la segunda égloga ("quedé yo entonces como quien camina/ de noche por caminos arriscados"); también se encuentra en el soneto XVII ("pensando que el camino iba derecho"), y una lectura aleatoria muestra diversas formas de este camino en la poesía de Garcilaso. Para E. GLACER es "la imagen del viandante que contempla la senda 
ciada a la melancolía, nada extraña que, a falta de documento autógrafo, el texto sea rico en variantes ${ }^{4}$ dictadas por otras tantas lecturas o memorias, que pueden cambiar algo el léxico de ciertos versos, pero no su estructura. $\mathrm{Al}$ analizar la sintaxis de cada estrofa se advierte en qué detalles esas lecturas o memorias introdujeron cambios que por eufonía o gustos se antojaron más coherentes. Una de las lecturas del primer cuarteto (denominada $O$ ) reescrito en numerosas imitaciones dice,

Cuando me paro a contemplar mi 'stado y a ver los passos por do m'ha traýdo hallo, según por do anduve perdido, que a mayor mal pudiera aver llegado.

La composición comienza in medias res, y la lectura se detiene en esa especie de exordio, de captatio benevolentia, que dicta el comentario de Herrera citado en la nota 2; pero, y a pesar de Herrera, no creo que sea "prefación" de obra ni de amores, sino una torcedura en la sintaxis, que no es muy complicada. La oración principal, "hallo que a mayor mal pudiera haber llegado" -compuesta de sujeto, verbo y objeto directo en la subordinada- tiene por contexto la circunstancial introducida con un adverbio relativo temporal ("cuando me paro... y a ver los pasos por do...") ${ }^{5}$ más la incidental ("según por do anduve perdido") introducida también por un adverbio relativo, esta vez de modo. En esta lectura, mi stado, objeto directo de la circunstancial, resulta sujeto del verbo en singular "ha traído".

Otras lecturas - una del Brocense, las versiones $M g$ y $M a-$ cambian el verbo del segundo verso al plural ("los passos por do me han traído"), con lo que passos se convierte en sujeto. Aunque los críticos coinciden en la naturaleza espiritual del 'stado y los passos, han entablado una discusión -aunque sin pasión, insistente- sobre esta variante, pero ni la discusión ni las normas de la ecdótica cambian el sentido del cuarteto: verbo en singular o plural, el 'stado es un hecho misterioso, que se aclara, o resulta menos misterioso, al iniciar el primer terceto.

recorrida" (Estudios hispano-portugueses, Castalia, Valencia, 1957, p. 63), conclusiones obvias, que, como la del Brocense, no añade mucho a la materia del soneto.

${ }^{4}$ Cuando tenía escritas estas páginas encontré el artículo de NADINE Ly sobre este soneto en Criticón, 74 (1998), 9-29; exhaustivo en cuanto a variantes y antecedentes.

${ }^{5}$ Esta subordinada, dice Herrera, es un "zeugma”, que significa en español ligadura o ayuntamiento; cuando un verbo se llega comúnmente a muchas sentencias y conviene a todas con igual significado, como éste, que se refiere a "contemplar" y "ver". Según la retórica tradicional, éste sería un zeugma no complejo, que se encuentra entre la figuras per detractionem (Quintiliano, Institutionis oratoriae, IX, iii, 62 s.). 
Quienes prefieren el verbo en plural ${ }^{6}$ arguyen cuestiones sintácticas y semánticas de tono parecido (es más clara, dice Rivers, una frase como "a ver por dó me han traído los pasos"); Blecua opina que un verbo de movimiento no combina con una situación estática; "no encuentro, dice, ejemplos que puedan apoyar el uso de mi estado me ha traído por...", anormalidad semántica que "todos los recreadores procuran soslayar", de modo que acomodan el segundo verso a lo que podría calificar de "sentido común gramatical" (por ejemplo, "y veo los pasos por donde he venido", "y a ver los passos por donde he venido"). Morros se hace eco de esta opinión, y lo que para Rosso Gallo $^{7}$ es (y para Blecua puede ser) una lectio difficilior-el sujeto 'stado y el objeto directo los passos-, para Morros es "construcción agramatical"; al sugerir el crítico que imitaciones y traducciones usan "la tercera persona con el verbo de movimiento", supongo que se refiere a simple agramaticalidad, no a la peregrina idea de Riffaterre, quien define así las "alteraciones" (la teratología, quizá) que dan carácter al texto poético ${ }^{8}$. En cualquier manifestación de la lengua, se podría hablar de agramaticalidad cuando se trata de falta de concordancia, inconsciente o voluntaria, pero no hay agramaticalidad en estos versos, cualquiera sea la lectura que se prefiera. Atenidos demasiado a la ortodoxia, semántica o gramatical, se olvida la libertad poética y la licencia metafórica ${ }^{9}$.

No obstante, es evidente la incomodidad - ¿gramatical acaso?de copistas (o lectores) e imitadores respecto a "passos", porque en $M a-$ la versión más "alterada" -, quien la dejó como otro testimonio eliminó todo misterio, ambigüedad gramatical y semántica al transcribir "y a ver mis pasos por do me han traído". Si con "los pasos" puedo argüir que se trata de 'camino' o sus sinónimos, y de que muy bien

${ }^{6}$ E. Rivers en su ed. de la Obras completas ya citada; B. Morros, Obra poética y textos en prosa, Crítica, Barcelona, 1996; J. M. Blecua, En el texto de Garcilaso, Ínsula, Madrid, 1970. También LAPESA, en la transcripción del primer cuarteto opta por el plural sin detenerse a lucubrar en la variante singular (La trayectoria poética de Garcilaso, $3^{a}$ ed., Istmo, Madrid, 1985, p. 76).

${ }^{7}$ La poesía de Garcilaso de la Vega. Análisis filológico y crítico, Real Academia Española, Madrid, 1990.

8 Semiotics of poetry, Bloomington, Indiana, 1984, p. 2.

${ }_{9}^{9}$ Aunque no es imprescindible, copio algunas líneas de un viejo estudio de AмADO Alonso ("Sobre métodos: construcciones con verbos de movimiento en español", en su libro Estudios lingüisticos. Temas españoles, Gredos, Madrid, 1951, pp. 235 s.): "lo estilístico del español es el uso de gran número de verbos de movimiento con cambios semánticos, en los que la significación ya no es la primaria de movimiento físico, pero conserva ciertos elementos representacionales de movimiento cuyo valor expresivo hay que determinar en cada caso... Lo que determina la unidad es la tendencia genial de nuestra lengua a presentarse en movimiento interno gran número de actividades, de acontecimientos y aun de estados". Ejemplos de esta naturaleza se encuentran también en el Diccionario de construcción y régimen de Cuervo, s.v. "traer". 
sigue siendo 'stado el sujeto de un verbo en singular, con el posesivo y el verbo en plural todo ese argumento se desploma.

Quedan la incidental, "según por do anduve perdido", que a nadie causa problemas, y la oración principal, "hallo que a mayor mal pudiera haber llegado", que, por la naturaleza marcadamente anímica de, perdido, mal, podrían dar lugar a interpretaciones de la misma índole que los dos primeros versos. En todo caso, el subjuntivo de la subordinada objeto directo ("pudiera haber"), señala una duda (puede ocurrir o no) que se repite en las condicionales de los versos 11-12 y en el gerundio del último. El segundo cuarteto

mas cuando del camino 'stó olvidado

a tanto mal no sé por dó he venido;

comienza, en realidad, con otra circunstancial temporal, "cuando del camino estó olvidado"; y con esa extraña adversativa "mas a tanto mal no sé por dó he venido" - cuya oración principal, "no sé", tiene una subordinada objeto directo al mismo tiempo modal y cuantitativa "a tanto mal", seguida de una circunstancial de lugar "por dó he venido"-, termina el tono reflexivo que caracteriza lo que podríamos denominar primera parte temática del soneto. Digo extraña porque es negación del primer cuarteto e incombinable con el resto de la composición; es una especie de cuña - ¿de after thought? - que apenas tiene, a pesar de la observación de Blecua que copio abajo, conexión temática con los versos que siguen, y la sintaxis no se altera:

Sé que me acabo y más he yo sentido ver acabar conmigo mi cuydado.

Es curioso que por medio de la puntuación se procure relacionar los ocho primeros versos, como si ese cambio notable en el séptimo ("sé que me acabo...") no alterara la reflexión de los primeros, en los que predomina la duda (pudiera, no sê). Al comparar las versiones $O$ y $M a$, Blecua favorece ésta como primera composición, porque "el tránsito de la primera parte del soneto (1-7) a la segunda (8-14) es menos brusco: Al volver... el poeta sobre el soneto, el paso sintáctico e ideológico entre las dos partes es más cortado, menos unitario, si bien gana en dramatismo y en perfección conceptual” (p. 25). Es otra lectura $^{10}$. El cuarteto de $M a$ dice

${ }^{10}$ La versión Ma está transcrita, al parecer, ad libitum y el buen supuesto de Blecua (falló la memoria del que lo reprodujo), del que se hace eco la casi afirmación de Rosso Gallo ("me parece más digna de confianza la hipótesis de una transcripción hecha de memoria") debería ser certeza. En épocas sin nuestros medios de documentación, la memoria era con frecuencia, si no la fuente más confiable, la única. Es casi lo mismo que ocurre con el soneto 28 ("Amor, amor, un ábito vestí/ el 
Mas cuando del camino estó olvidado, a tanto mal no sé cómo he venido; mucho más que perderme he yo sentido el perder conmigo mi cuidado.

Quien lo copió, o lo rehizo, elimina el "por do”, “por do”, “por dó", que en $O$ se combina con los "cuando", "cuando", intencionadamente anafóricos, pero ese no es problema que altere la estructura del cuarteto; el uso de "perder" en vez de "acabar" no cambia la naturaleza de la frase; sigue siendo una causal: "[porque] sé que me acabo..."; "[porque] mucho más que perderme...", ni deja de ser una sustantiva objeto directo el octavo verso, señalada aún más por el artículo. Esos cambios, aunque hagan la tensión más sencilla o menos brusca - si coincidimos con Blecua- no simplifican la sintaxis ni alteran el sentido; simplemente los versos son algo torpes.

En el primer terceto ("Yo acabaré, que me entregué sin arte/ a quien sabrá perderme y acabarme,/ si quisiere, y aun sabrá querello") continúa la secuencia de subordinada causal "[porque] me entregué sin arte...", y por fin, en la subordinada objeto indirecto "a quien sabrá perderme...", la razón del 'stado en que se encuentra, más la incidental condicional "si quisiere".

En algunas versiones, las de Blecua y Rivers, se acentúa aun convirtiendo la partícula en un adverbio temporal. Creo que este y aun tiene aquí la misma función que el y más ("y más he yo sentido") del verso 7; en ambos casos se trata de coordinadas modales: "e incluso (hasta) he sentido", "e incluso (hasta) sabrá".

Quizá el último terceto ("pues que mi voluntad puede matarme/ la suya, que no es tanto de mi parte/ pudiendo, ¿qué hará sino hacello?”) sea el conjunto menos sencillo, y en él se advierte que las variantes pueden ser opiniones críticas que intentan perfeccionar el texto. Herrera anota el cambio etimológico propuesto por Barahona de Soto de "puede" por "quiere", a modo de hacer con los dos tercetos un silogismo; Tamayo de Vargas propuso dejarlo como estaba, pero cambiar el gerundio a "queriendo".

En la lectura de paso, se ocurre de inmediato que, por su marca ("pues que"), el terceto comienza con una causal ("[porque] mi voluntad...”), y es tentador clasificarla así, porque la estructura del terceto anterior es causal-condicional. Pero se trata de una condicional. Lo que contribuye a la condicionalidad o posibilidad (así como el subjuntivo de verso 11, "quisiere") en el verso 12 es el verbo

cual de vuestro paño fue cortado"), una de cuyas variantes ("un ábito he vestido/ del paño de tu tienda bien cortado", etc.), no debería infundir tantas dudas, aun al que está sometido a las normas de la ecdótica. La escritura de Garcilaso es económica y directa. 
"poder". La prótasis "si mi voluntad puede matarme", tiene en la apódosis "la suya, ¿que hará sino hacello?" otra condicional contenida en "pudiendo", gerundio referido al sujeto "la suya".

Dato obligado al hablar del soneto es el políptoton, atribuido por los críticos a resabios de la poesía cancioneril. Glacer alude a las dificultades impuestas por esa figura, "que hace extraordinariamente difícil la rápida lectura de los tercetos sin perderse en ese laberinto intelectual, aunque el sentido general resulte claro" ${ }^{11}$. Prescindiendo de que no hay necesidad de leer rápidamente los tercetos, de que el sentido general no es tan claro, pero tampoco un laberinto, ese políptoton de tipo anafórico, voluntarioso, en el cual se combinan presentes, futuros, subjuntivos, infinitivos, es lo que realmente marca el soneto y de manera muy especial. En realidad el políptoton no está en los dos tercetos; se encuentra ya en el segundo cuarteto: "no sé", "sé que me acabo", "ver acabar" y termina en el primer terceto "acabaré", "sabrá acabarme", "sabrá querello". Esta serie tiene como marco la incertidumbre que contienen el subjuntivo del cuarto verso ("pudiera haber"), la incidental del once ("si quisiere") y el gerundio del último ("pudiendo"). Es probable que esa manera de alentar en las afirmaciones y contener en los supuestos haya convertido el primer soneto en fuente de especulaciones -incluidas las extrapoéticas-, de polémicas eruditas, y, mejor aún, que nada definitivo se haya dicho hasta ahora sobre él.

Martha Elena Venier El Colegio de México 